\title{
Giovanni Battista Grassi.
}

27th Mareh 1854-4th May 1925.

Giovanni Battista Grassi was born at Rovellasca, Province of Como, and received his training in zoology and in medicine in the University of Pavia. The whole of his subsequent work was zoological, but his medical training was of considerable advantage in his numerous researches on the Protozoa and Helminthes parasitic in man and animals.

He was appointed Professor of Zoology in the University of Catania in 1883, and remained there until 1895 when he was promoted to the Chair of Comparative Anatomy in the Regia Università, Rome, where the last thirty years of his active life were spent.

Of his many contributions to knowledge only a few of outstanding importance can be referred to in this brief notice.

His first investigation, begun on his own initiative when he was a fourth-year student, was on anæmia in the cats of Rovellasca; and in a paper published in 1878 , he showed that the anæmia was due to the presence in the cat's intestine of a species of Ancylostoma ( $A$. balsami=caninum), a nematode worm. During the course of this work he instituted the sound method of determining the presence of the worm in the intestine by finding the characteristic eggs in the frces, and he applied the same method to detecting the infection of man with Ancylostoma duodenale. This worm is one of the most serious and frequent parasites of man in warmer countries; heavy infections produce severe anæmia and debility, and have resulted in numerous deaths. The discovery of a certain and rapid method of diagnosis was therefore a matter of prime importance. Grassi contributed other important helminthological observations, e.g. on the mode of infection of man by the round worm Ascaris lumbricoides, and on the tapeworm Hymenolepis, which he showed could complete its life-cycle in one host.

In protozoology he made notable advances in our knowledge of Entamceba coli, of Giardia intestinalis, and of the remarkable flagellates in the gut of Termites; and in his well-known Studii di uno Zoologo sulla Malaria (1900), with its beautiful illustrations, gave a wonderfully full picture of the various stages of the organisms of malaria in man and in the Anopheles mosquito.

VOL. XLV. 
As a student of the Arthropoda he was equally accomplished, as is evidenced by his splendid work (with Sandias) on the constitution and development of the society of Termites (1893, 1894), his investigations extending over many years culminating in a fine volume, in 1912, on the life-history and methods of control of Phylloxera-a serious enemy to vines, his account (1907) of Phlebotomus papatasii-the first satisfactory description of the structure and life-history of a sand fly (proved in 1909 to be the transmitter of a three-day fever which has come to be known as "sand-fly fever"), and his more recent papers on the biology of mosquitoes.

In the domain of marine biology also, Grassi made distinguished contributions. In 1883 his well-known monograph on the Chætognatha was published by the Naples Zoological Station, and not long after he went to Catania he began, with Calandruccio, a series of researches on the life-history and metamorphosis of the eels, the results of the last of which-on the metamorphosis of the Murænoids-were published in 1913. These researches largely dispelled the mystery in which the life-story of the eel had been enwrapped since the time of Aristotle.

Grassi was full of enthusiasm, and enlisted his colleagues and his pupils as collaborators in some of the investigations. In a few cases, unfortunately, this arrangement led to disagreement in regard to the apportionment of the credit for new discoveries. More serious was the controversy on the priority of the discovery of the cycle of human malaria, but this cannot prevent warm recognition of the excellence of Grassi's work on the parasites concerned.

His own researches and those which he inspired others to accomplish are of extent and importance fully to justify the statement that he was among the most fruitful zoological investigators of our time. Grassi's unbounded energy, vigorous personality, and wide interests made a deep impression on the writer on the three occasions when he visited the Institute of Comparative Anatomy in Rome.

Grassi was awarded the Darwin Medal of the Royal Society of London in 1896, was elected a Fellow of the Reale Accademia dei Lincei in 1897 (he had received the Premio Reale in 1888), and was made a Senator of the Kingdom of Italy in 1908. This Society elected him to the Honorary Fellowship in 1916.

J. H. A. 